\title{
Current distribution in a rectangular flow channel manufactured by 3D-printing
}

\author{
H.A. Figueredo-Rodríguez, R.D. McKerracher, C. Ponce de León*, F.C. Walsh
}

Electrochemical Engineering Laboratory, Energy Technology Research Group, Faculty of Engineering Sciences, University of Southampton, Highfield,

\section{Abstract}

Southampton, SO17 1BJ, United Kingdom

The characterization and improvement of a rectangular channel electrolyte flow compartment used in an iron-air flow battery was carried out by using an arrangement of copper electrodes to measure the current density distribution employing the limiting current technique. The present work addresses the hydrodynamics and mass transport distribution in the compartment and their improvement by an improved electrolyte compartment that results in a more uniform current distribution. The current distribution was evaluated as the ratio between the local and the averaged limiting current densities during the reduction of copper ions over a range of mean linear flow velocity across the electrode surface $\left(2-30 \mathrm{~cm} \mathrm{~s}^{-1}\right)$.

The initial compartment, showed larger differences between the minimum and maximum currents than the electrolyte compartment that resulted as part of the design process and showed a higher pressure drop at a given mean linear flow velocity.

Keywords: 3D printing, current distribution, electrolyte compartment, mass transport, pressure drop

* Author for correspondence: E-mail: capla@soton.ac.uk 


\section{Introduction}

The energy demands of modern society, together with its supply and distribution, pose challenging problems. Finding a solution without compromising future generations will require our energy infrastructure to be transformed by allowing a greater, more managed contribution from renewable energy sources. At the same time, the present energy conversion systems should adopt new technologies to become more versatile and efficient. These crucial issues, together with the need of the automotive industry to develop electric and hybrid vehicles, have triggered new research approaches in energy storage technologies.

Fuel cells, redox flow batteries and metal-air batteries have been highlighted due to their potential to deliver a high specific energy at moderate cost. In particular, metal air batteries, such as zinc- aluminium- and iron-air batteries, have received increasing attention due to the low cost and natural abundance of the metals and air together with their ease of electrical recharging. Iron-air batteries have advantages during the recharging cycle compared to zinc-air batteries, which have a tendency to form zinc dendrites at the negative electrode upon repeated cycling ${ }^{1}$. Figure 1 shows that the specific energy and theoretical capacity of the iron-air battery compare well with zincair batteries ${ }^{2,3}$. There remain many challenges for the development of the iron-air battery, including the low cell voltage due to slow reduction and passivation of the iron electrode due to the formation of insoluble and non-conductive oxides on discharge and slow evolution of oxygen on charge. Recent advances in nanotechnology have enabled lower oxygen reaction overpotentials by the use of catalytic nanostructured materials and improvements in the reversibility of iron ${ }^{4,5,6}$. 
When designing an electrochemical iron-air battery, it is important to consider that having an even current distribution is essential for efficient operation and durability of the battery. In particular, the geometry of the flow channels, the position and orientation of the electrolyte ports and a uniform flow environment in the cell are important aspects of the cell design. The flow channel must ensure favourable hydrodynamics that allow the electrolyte to flow freely with moderate frictional resistance, promoting uniform electrochemical reaction across all of the available electrode surface area during both charge and discharge. A practical way to characterize the cell performance is by measuring the pressure drop and the mass transport characteristics via the limiting current technique under different flow conditions.

Many electrochemical processes are mass transfer limited due to the convectivediffusion of the reacting species towards the electrode surface. The mass transfer rate may be increased by the electrolyte flow velocity, facilitating gas evolution at the electrode surface, or using inert turbulence promoters ${ }^{7}$. Each of these solutions has advantages and limitations. An increased electrolyte flow velocity will reduce the diffusion boundary layer but extra pumping energy will be required. The evolution of gas at the electrode surface causes a disruption of the boundary layer but the local $\mathrm{pH}$ may be upset; gas stirring requires a relatively high electrolyte velocity to achieve uniform mixing, which results in higher pumping and more stringent sealing requirements. In contrast, the use of inert turbulence promoters in the flow channel is a simple, low cost approach to increase the mass transfer by investing a little extra pumping energy to facilitate the incremental rise in pressure drop across the cell. 
These considerations must be taken into account when a practical prototype is designed and can be studied in detail using both mathematical simulation ${ }^{8}$ and laboratory measurements for an electrochemical reactor. There are numerous studies on the characterization of electrochemical systems ${ }^{7-12}$ and there is an extensive literature related to this topic e.g. ${ }^{13,14}$. An important aspect of the characterization is the measurement of space-time averaged values of limiting current for a model mass transport controlled reaction, as in a previous study ${ }^{9}$.

The present work focuses on the limiting current technique to characterize the hydrodynamic and mass transport performance of an electrochemical cell used as an iron-air battery. The distribution of limiting current over the electrode length is examined directly using copper electrodes following previous work ${ }^{7}$. The novelty of the present investigation is to show that by using information from the mass transport performance of a channel flow cell, a rapid redesign and construction of new improved version of the channel could be manufactured by 3D printing.

\section{Experimental details}

\section{Electrochemical cell}

A prototype cell was manufactured by traditional computer numerical control (CNC) routing techniques to test the iron-air battery system as part of the EU NECOBAUT project ${ }^{15}$. The cell is composed of a series of polymer plates, sealing gaskets, electrolyte channels, electrodes, electrolyte inlets/outlets and air inlets/outlets compressed between two stainless steel plates $(14.0 \times 19.0 \times 1.0 \mathrm{~cm})$ with 6 A2-70 
stainless steel bolts of $1 \mathrm{~cm}$ diameter and $75 \mathrm{~mm}$ length as shown in Figure 2. The image also shows the copper plate counter electrode and the polymeric flat plate containing the 20 oval copper electrodes within an area of $5 \times 5 \mathrm{~cm}$ exposed to the electrolyte. The cell operated with a single electrolyte compartment $(15 \times 10 \times 0.5 \mathrm{~cm})$ machined from PVC. Subsequent designs of the compartment were manufactured by 3D printing in acrylonitrile butadiene styrene (ABS). The electrolyte compartment had a $1 \mathrm{~mm}$ circular orifice on one side to insert the Luggin capillary connected to an $\mathrm{Ag} / \mathrm{AgCl}$ reference electrode compartment. Figure 3 shows a comparison between the electrolyte compartment manufactured by $\mathrm{CNC}$ techniques in Figure 3a) and the 3D printed modifications in Figure 3b) and 3c). The prototypes in Figure 3b) and 3c) were manufactured by a BFB 3D-printer, using ABS. The 3D printing technique allows freedom with design features and is a convenient technique for fast prototyping design and construction. In the following discussion, the compartments shown in Figure 3a), $3 \mathrm{~b})$ and $3 \mathrm{c}$ ) are referred to as compartments 1, 2 and 3. The experimental characteristics of the cell are listed in Table 1.

\section{Electrode arrangement}

The investigation of the current-distribution within the cell followed a similar approach to that reported in references ${ }^{7}$ and ${ }^{16}$ that used segmented electrodes. Instead of segmented electrodes, an arrangement of 20 oval copper electrodes $(3.8 \times 5 \mathrm{~mm})$ of $0.61 \mathrm{~cm}^{2}$ area each, was used. The electrodes were evenly distributed within the $25 \mathrm{~cm}^{2}$ area window open in the electrolyte compartment as shown in Figure 4. The 20 electrodes were manufactured using a printed circuit board (PCB) covered with a UV 
sensitive layer. The procedure to form the electrodes includes exposing the unwanted regions of the PCB to UV radiation which allows the UV sensitive layer to be removed with $\mathrm{NaOH}$ solution $\left(1 \mathrm{~g}\right.$ in $\left.100 \mathrm{~cm}^{3}\right)$. The $\mathrm{PCB}$ was then immersed in a $\mathrm{FeCl}_{3}$ solution ( $25 \mathrm{~g}$ in $100 \mathrm{~cm}^{3}$ ) to remove the cooper from the exposed areas. The 20 identical oval electrodes of $0.61 \mathrm{~cm}^{2}$ area provided a total active electrochemical surface area of 12.25 $\mathrm{cm}^{2}$. Figure 4 shows the image of the plate that contains the oval electrodes and their electrical connection. The current flowing through each oval electrode was monitored by the voltage drop across a $1 \Omega$ shunt connected in series to each electrode as shown in Figure 5. The potential drop was proportional to the current and was monitored by a National Instruments NI USB-6225 data acquisition system and converted to the corresponding current values to produce the current $v s$. potential curves for each electrode.

\section{Electrolyte system and pressure drop}

Figure 5 also shows a schematic diagram of the electrolyte circuit that includes a centrifugal pump (Totton EMP440/4) a polymeric flow meter able to measure within the range of $0-100 \mathrm{dm}^{3} \mathrm{~h}^{-1}$ (George Fisher Type SK52) and an Autolab potentiostatgalvanostat PGSTAT 302N all attached to the electrochemical cell. The solution was prepared with distilled water and reagent grade chemicals. The electrolyte was recirculated through the cell from a $1.5 \mathrm{dm}^{3}$ reservoir capacity containing $1 \mathrm{dm}^{3}$ of $5 \times$ $10^{-3} \mathrm{~mol} \mathrm{dm}^{-3} \mathrm{CuSO}_{4}$ in $1.5 \mathrm{~mol} \mathrm{dm}^{-3} \mathrm{H}_{2} \mathrm{SO}_{4}$ electrolyte. Before the cell was assembled the copper counter electrode plate and the oval cathode electrodes were polished with 1200 grade emery paper followed by $0.1 \mu \mathrm{m}$ alumina powder, then washed with 
distilled water and degreased with acetone. The electrolyte was purged with nitrogen gas for a period of $15 \mathrm{~min}$ and nitrogen sparging was maintained during the experiments to minimise the influence of the reduction of dissolved oxygen. The physicochemical properties of the electrolyte are summarised in Table 2.

The pressure drop was measured with a digital manometer (Digitron model 2028P) between the electrolyte entrance, and the electrolyte exit, after passing though the cell that included a distribution manifold as shown in Figure 5.

\section{Potentiostat configuration}

The potential of the 20 working electrodes was swept from $-0.050 \mathrm{~V}$ to $-0.600 \mathrm{~V} v s$. $\mathrm{Ag} / \mathrm{AgCl}$ at a scan rate of $10 \mathrm{mV} \mathrm{s}^{-1}$ at $298 \mathrm{~K}$. The individual current through each electrode was monitored with the data acquisition system using a series of shunt resistors while the total current was recorded by a potentiostat-galvanostat PGSTAT $302 \mathrm{~N}$.

\section{Results and discussion}

Typical current, $I v s$. potential, $E$ curves were measured during the reduction of cupric ions between $-0.3 \mathrm{~V}$ and $-0.5 \mathrm{~V} v s . \mathrm{Ag} / \mathrm{AgCl}$ at different electrolyte flow rates. These experimental plots were carried out for all the cell compartments (Figure 3a)-3c)) and are presented in Figures $6 a)-6 c$ ) respectively. It should be point out that the measured current $I$, through the cell is the sum of the 20 individual currents measured at each one of the 20 oval electrodes and in this section we will refer to it as the total current $I$. Simultaneously, the individual currents $I_{i}$ at each oval electrode were measured using 
the data acquisition system. The ideal scenario would be that, where the reaction happens as uniform as possible this would imply that the measured current at each one of the individual electrodes would be the same. A way to normalise the results highlighting how uniform the reaction occurs is by presenting the ratio $I_{i} / I_{\mathrm{AVG}}$ (or $j_{i} / j_{\mathrm{AVG}}$ equivalent) where $I_{\mathrm{AVG}}$ (or $j_{\mathrm{AVG}}$ equivalent) is the average value of all the $I_{i}$ (or $j_{i}$ equivalent) values chosen at a particular potential in this case in the limiting current region at $-0.4 \mathrm{~V} v s . \mathrm{Ag} / \mathrm{AgCl}$.

The $j_{i} / j_{\text {AvG }}$ ratio was evaluated for each electrode and indicates how uniform the limiting current density distribution is for different electrolyte compartments. A value of 1 for $j_{i} / j_{\mathrm{AVG}}$ means that the limiting current density of a particular electrode is the same as the mean value measured for all the electrodes, though is a measure of how uniform the limiting current distribution is in this region.

The $j_{i} / j_{\mathrm{AVG}}$ ratio was calculated for each electrode when the different electrolyte compartments in Figure 3a) to 3c) were used during the reduction of cupric ions:

$$
\mathrm{Cu}^{2+}+2 \mathrm{e}^{-} \rightarrow \mathrm{Cu} \quad E^{o}=0.3419 \mathrm{~V} v s . \text { SHE }
$$

Figures $7 \mathrm{a})-7 \mathrm{c}$ ) show plots of the ratio $j_{i} / j_{\mathrm{AVG}}$, for each of the 20 electrodes when the electrolyte compartments 1, 2 and 3, respectively, were used. The different colour lines indicate different flow rates (flow velocities passing the electrode surface) from $10 \mathrm{dm}^{3}$ $\mathrm{h}^{-1}\left(2.8 \mathrm{~cm} \mathrm{~s}^{-1}\right)$ to $100 \mathrm{dm}^{3} \mathrm{~h}^{-1}\left(27.7 \mathrm{~cm} \mathrm{~s}^{-1}\right)$. The curves show that the ratio of the current density for all the compartments varies around 1, but the current distribution in the 
original compartment (compartment 1) has a larger number of electrodes with a ratio $j_{i}$ $/ j_{\mathrm{AVG}}$ higher and lower than 1 ; for example electrodes 9 and 15 reach ratios of 0.8 and 1.2 respectively, suggesting that the electrolyte flow was not uniform in some regions when this compartment was used. The compartments 2 and 3 show that, for all the electrodes the $j_{i} / j_{\mathrm{AVG}}$ is closer to 1 , except in the electrode 18 in compartment 3 that shows a ratio of 0.65 at $22.2 \mathrm{~cm} \mathrm{~s}^{-1}$ mean linear flow rate. This low value of $j_{i} / j_{\mathrm{AVG}}$ indicates a low limiting current density which can be explained by looking at the shape of the flow distributor in the electrolyte compartment in Figure 3c) where the position of electrode 18 coincides with the solid part of the flow distributor and suggests that the local electrolyte flow velocity is lower, resulting in lower limiting current density. Figure 7 shows that the electrolyte compartment 2 performance resulted in a more uniform limiting current distribution.

A more visual representation of the limiting current distribution can be obtained by using the data from the average and local limiting current densities to interpolate the limiting current density between the electrodes. Figures 8a), 8b) and 8c) show a comparison over electrolyte compartments 1,2 and 3 at a flow rate of $100 \mathrm{dm}^{3} \mathrm{~h}^{-1}(27.7$ $\mathrm{cm} \mathrm{s}^{-1}$ ). Figure 8a) shows that the electrolyte compartment 1 experienced large variations of limited current density distribution, indicated by the change of colour from red (low limited current density) to blue (high limited current density) whereas the colours in the surface plot that represent compartment 2 and 3 are slightly more uniform, see Figures $8 b$ ) and $8 c$ ). In the electrolyte cell design 2 the $j_{i} / j_{\text {AVG }}$ distribution tends to increase towards the right, which can be explained by looking at the electrolyte compartment geometry in Figure $3 b$ ) where the inlet distribution channels direct the 
electrolyte to the right, increasing the local flow rate on the right hand side while favouring recirculation on the left hand side.

In order to increase the flow uniformity in compartment 3 , the initial inlet flow channels have a geometry that helps to direct the flow upwards as seen in figure $3 \mathrm{c}$ ) this resulted in a smoother and more uniform performance than in the previous two designs as can be observed by comparing Figures 8 a), 8 b) and 8 c) in which the surface curve in 8 c) is the one in which the $j_{i} / j_{\mathrm{AVG}}$ had the smallest variation.

\section{Pressure drop}

A comparison of the pressure drop across the electrochemical cell fitted with the electrolyte compartments 1,2 and 3 is presented in Figure 9. The pressure drop is a measure of the overall resistance to flow in the cell and the Figure 9 shows the pressure drop from the FM01 electrolyser reported in the literature ${ }^{15}$ for comparison. Electrolyte compartments 2 and 3 have a lower pressure drop, as the Reynolds number increases. The values are lower than that those reported for the FM01 electrolyser. The pressure drop $\Delta P$ follows a simple power function of the Reynolds number of the type:

$$
\Delta P=a R e^{b}
$$

The Reynolds number is defined as:

$$
R e=v \cdot d_{e} / v
$$


where $\mathrm{v}$ is the mean electrolyte linear flow velocity in the rectangular channel $(v=Q$ / $B S)$ and $d_{e}$ is the equivalent diameter of the channel, $d_{e}=2 B S /(B+S)$ The values of $a$ and $b$ are reported in Table 3 and the results clearly show that the design of the electrolyte compartments 2 and 3 offer lower pressure drops. The pressure drop is of fundamental importance when considering the pumping cost requirements for the hydraulic system ${ }^{17}$.

The mass transport coefficient was also calculated for the total current observed during the reduction of copper ions in the three electrolyte compartments, using the equation (2) below and correlated with the pressure drop:

$$
k_{\mathrm{L}}=I_{\mathrm{L}} / z F A c
$$

where $k_{\mathrm{L}}$ is the mass transport coefficient, $I_{\mathrm{L}}$ the limiting current, $z$ the number of electrons transferred, $F$ the Faraday constant, $A$ the electrode area and $c$ the concentration of the electroactive species. Figure 10 shows the development of the mass transport coefficient at the corresponding pressure drop calculated at the same mean linear flow rate. The variation of the mass transport coefficient also follows a simple power law relationship of the form:

$$
k_{\mathrm{L}}=q \Delta P^{\mathrm{r}}
$$


with $q$ and $r$ being empirical constants. The values of $q$ and $r$ are reported in Table 3 together with Figure 10. 3D printing design offers higher values of mass transport at a given pressure drop. Lower pressure drop and high mass transport rates represent economic cost factors and this is a simple way to appreciate the technical performance $v s$. economic cost in a cost-benefit fashion.

\section{Conclusions}

The original electrolyte compartment showed a reasonably uniform current density distribution which can be concluded by the fact that the $j_{i} / j_{\mathrm{AVG}}$ term did not significantly deviate from unity. Nevertheless, the improved designs showed an improved distribution after modifying the geometry of the channel as a result the feedback provided by the mass transport characteristics. 3D printing technologies allows to accelerate the redesign-manufacture cycle process of the flow channel.

The pressure drop measurements also show that the improved electrolyte compartment have lower pressure drop at the same Reynolds number than the original flow compartment and present higher mass transport coefficients at the same pressure drop.

The methodology presented in this paper could readily be used to evaluate the performance of new prototypes leading to an optimised design. 3D-printing techniques have proved to be a very flexible and fast manufacturing alternative to improve the process of electrochemical flow cell design. 


\section{Acknowledgments}

This work was enabled by an EU grant FP7 (NECOBAUT Grant agreement no. 314159). H.A. Figueredo is grateful to CONACYT for the scholarship and financial support. All data supporting this study are openly available from the University of Southampton repository at http://dx.doi.org/10.5258/SOTON/399736.

\section{Notation}

\begin{tabular}{|c|c|c|}
\hline Symbol & Meaning & Units \\
\hline$a, b$ & Coefficients in equation (2) & \\
\hline$A$ & Electrode area & $\mathrm{cm}^{2}$ \\
\hline$A_{X}$ & Cross-sectional area of rectangular flow channel & $\mathrm{cm}^{2}$ \\
\hline$B$ & Breadth of flow channel & $\mathrm{cm}$ \\
\hline$c$ & Concentration of cupric ions & $\mathrm{mol} \mathrm{cm}$ \\
\hline$d_{e}$ & Equivalent diameter of rectangular flow channel & $\mathrm{cm}$ \\
\hline$D$ & Diffusion coefficient of cupric ions & $\mathrm{cm}^{2} \mathrm{~s}^{-1}$ \\
\hline$E$ & Potential & $\mathrm{V}$ \\
\hline$F$ & Faraday constant & $\mathrm{C} \mathrm{mol}^{-1}$ \\
\hline$I$ & Current & A \\
\hline$I_{\mathrm{L}}$ & Limiting current for copper deposition & $\mathrm{A} \mathrm{cm}^{-2}$ \\
\hline$j$ & Current density & $\mathrm{A} \mathrm{cm}^{-2}$ \\
\hline$j_{A V G}$ & Average current density & $\mathrm{A} \mathrm{cm}^{-2}$ \\
\hline$k \mathrm{~L}$ & Mass transport coefficient & $\mathrm{cm} \mathrm{s}^{-1}$ \\
\hline$\Delta P$ & Pressure drop over the cell compartment & $\mathrm{Pa}$ \\
\hline$q, r$ & Coefficients in equation (5) & \\
\hline$Q$ & Volumetric flow rate of electrolyte & $\mathrm{cm}^{3} \mathrm{~s}^{-1}$ \\
\hline$S$ & Height of flow channel & $\mathrm{cm}$ \\
\hline$v$ & Mean linear flow velocity of electrolyte & $\mathrm{cm} \mathrm{s}^{-1}$ \\
\hline$z$ & Number of electrons transferred & Dimensi \\
\hline
\end{tabular}




\section{Greek}

$\begin{array}{lll}\eta & \text { Dynamic viscosity } & \mathrm{g} \mathrm{cm}^{-1} \mathrm{~s}^{-1} \\ v & \text { Kinematic electrolyte viscosity } & \mathrm{cm}^{2} \mathrm{~s}^{-1} \\ \rho & \text { Fluid density of electrolyte } & \mathrm{g} \mathrm{cm}^{-3}\end{array}$

\section{Dimensionless groups}

$\operatorname{Re}$

Reynolds number in rectangular flow channel

Dimensionless

\section{Abbreviations}

$\begin{array}{ll}\text { ABS } & \text { Acrylonitrile butadiene styrene } \\ \text { CNC } & \text { Computer numerical controlled } \\ \text { PCB } & \text { Printed circuit board } \\ \text { 3D } & \text { Three dimensional }\end{array}$




\section{Literature Cited}

1. Lin X, Pletcher D, Ponce-de-Léon C, Walsh FC, Wills RGA. Zinc based flow batteries for medium and large scale energy storage, Advances in batteries for large-and medium-scale energy storage. Eds. Menictas C, Skyllas-Kazacos M, Lim TM. Woodhead Publishing. 2014.

2. Jörissen L. Bifunctional oxygen/air electrodes. J. Power Sources. 2006;155:2332.

3. Price SW, Thompson SJ, Li X, Gorman SF, Pletcher D, Russell AE, Walsh FC, Wills RGA. The fabrication of a bifunctional oxygen electrode without carbon components for alkaline secondary batteries. J. Power Sources, 2014;259:4349.

4. McKerracher RD, Ponce-de-Léon C, Wills RGA, Shah AA, Walsh FC. A Review of the Iron-Air Secondary Battery for Energy Storage. ChemPlus Chem. 2015;80:323-335.

5. Manohar AK, Yang C, Malkhandi S, Yang B, Surya-Prakash GK, Narayanan SR. Understanding the factors affecting the formation of carbonyl iron electrodes in rechargeable alkaline iron batteries. Journal of Electrochemical Society. 2012;159-12:A2148-A2155.

6. Gil-Posada JO, Hall P. Post-hoc comparisons among iron electrode formulations based on bismuth, bismuth sulphide, iron sulphide and potassium sulphide under strong alkaline conditions. Journal of Power Sources. 2014;268:810-815.

7. Brown CJ, Pletcher D, Walsh FC, Hammond JK, Robinson D. Local mass transport effects in the FM01 laboratory electrolyser. J. Applied Electrochem., 1992;22:613-619. 
8. Vázquez L, Alvarez-Gallegos A, Sierra FZ, Ponce de León C, Walsh FC. Prediction of mass transport profiles in a laboratory filter-press electrolyser by computational fluid dynamics modelling. Electrochim. Acta. 2010;55:34463453.

9. Brown CJ, Pletcher D, Walsh FC, Hammond JK, Robinson D. Studies of spaceaveraged mass transport in the FM01-LC laboratory electrolyser. J. Applied Electrochem. 1993;23:38-43.

10. Ponce-de-León C, Reade GW, Whyte I, Male SE, Walsh FC. Characterization of the reaction environment in a filter-press redox flow reactor. Electrochim. Acta. 2007;52:5815-5823.

11. Ponce-de-León C, Whyte I, Reade GW, Male SE, Walsh FC. Mass transport and flow dispersion in the compartments of a modular 10 cell filter-press stack. Australian J. Chem. 2008;61:797-804.

12. Trinidad P, Walsh FC. Hydrodynamic behaviour of the FM01-LC reactor. Electrochimica Acta. 1996;41:493-502.

13. Pletcher D, Walsh FC. Industrial Electrochemistry (2nd edition). Glasgow: Springer, 1990.

14. Pickett DJ. Electrochemical Reactor Design (2nd edition). Amsterdam: Elsevier, 1977.

15. NECOBAUT. http://www.necobaut.eu/home/home.php. Accessed 7 July 2016. 
16. Tangirala R, Low CTJ, Ponce-de-León C, Campbell SA, Walsh FC. Copper deposition at segmented, reticulated vitreous carbon cathode in a Hull cell. Trans. Inst. Metal Finish. 2010;88:84-92.

17. Brown CJ, Walsh FC, Pletcher D. Mass transfer and pressure drop in a laboratory filterpress electrolyser. Trans IChemE. 1995;73:196-205.

18. Arenas L.F., Walsh F.C., Ponce de León C. 3D-printing of redox flow batteries for energy storage: A rapid prototype laboratory cell. ECS J Solid State Sci Technol. 2015;4:3080-3085. 
Table 1 Materials used and geometrical characteristics of the flow cell.

\begin{tabular}{|l|l|l|l|l|}
\hline Component & Materials & $\begin{array}{l}\text { Thickness } \\
\text { /mm }\end{array}$ & $\begin{array}{l}\text { Height } \\
\text { /mm }\end{array}$ & $\begin{array}{l}\text { Width } \\
/ \mathbf{m m}\end{array}$ \\
\hline End plate & $\begin{array}{l}\text { Stainless steel, } \\
\text { grade 316 }\end{array}$ & 10 & 190 & 140 \\
\hline Sealing gasket & Silicone rubber & 1.5 & 150 & 100 \\
\hline Counter electrode & Copper & 1 & 150 & 100 \\
\hline Sealing gasket & Silicone rubber & 1.5 & 150 & 100 \\
\hline $\begin{array}{l}\text { Electrolyte } \\
\text { compartment }\end{array}$ & Polypropylene & 5 & 150 & 100 \\
\hline Sealing gasket & Silicone & 1.5 & 150 & 100 \\
\hline $\begin{array}{l}\text { Segmented } \\
\text { (working) } \\
\text { electrode }\end{array}$ & $\begin{array}{l}\text { Copper on epoxy } \\
\text { or fibre glass } \\
\text { substrate }\end{array}$ & 1 & 150 & $\mathrm{ca} .200$ \\
\hline Gasket & Silicone rubber & 1.5 & 150 & 100 \\
\hline $\begin{array}{l}\text { End plate } \\
\text { Stainless steel, } \\
\text { grade 316 }\end{array}$ & 10 & 190 & 140 \\
\hline $\begin{array}{l}\text { Equivalent } \\
\text { diameter, } d e\end{array}$ & 0.909 cm & & & \\
\hline
\end{tabular}

Table 2 Electrolyte properties

\begin{tabular}{|l|l|}
\hline Property & Value \\
\hline Fluid density, $\rho$ & $1.096 \mathrm{~g} \mathrm{~cm}^{-3}$ \\
\hline Dynamic viscosity, $\eta$ & $0.0119 \mathrm{~g} \mathrm{~cm}^{-1} \mathrm{~s}^{-1}$ \\
\hline Diffusion coefficient of $\mathrm{Cu}^{2+}, D$ & $5.0 \times 10^{-6} \mathrm{~cm}^{2} \mathrm{~s}^{-1}$ \\
\hline Kinematic viscosity, $v$ & $0.01004 \mathrm{~cm}^{2} \mathrm{~s}^{-1}$ \\
\hline Temperature & $298 \mathrm{~K}$ \\
\hline
\end{tabular}

Table 3 Correlations to describe the relationship between pressure drop and Reynolds number or mass transport coefficient and pressure drop.

\begin{tabular}{|l|l|l|l|l|}
\hline \multirow{2}{*}{$\begin{array}{l}\text { Electrolyte } \\
\text { compartment }\end{array}$} & \multicolumn{3}{|c|}{$\Delta \boldsymbol{P}=\boldsymbol{a} \boldsymbol{R} \boldsymbol{e}^{\boldsymbol{b}}$} & \multicolumn{2}{c|}{$\boldsymbol{k}_{\mathrm{L}}=\boldsymbol{q} \Delta \boldsymbol{P}^{\boldsymbol{r}}$} \\
\cline { 2 - 5 } $\begin{array}{l}\text { Manufactured by CNC } \\
\text { machining, design 1 }\end{array}$ & 1.43 & 1.97 & 1.6 & 0.32 \\
\hline 3D printed, design 2 & 3.1 & 1.81 & 1.2 & 0.38 \\
\hline 3D printed, design 3 & 0.15 & 1.6 & & \\
\hline FM01-LC, literature [5] & 1780 & 1.5 & & \\
\hline
\end{tabular}




\section{Figure captions}

Figure 1 Comparison of the idealised performance of specific energy and specific charge capacity of different metal-air batteries [2].

Figure 2 Expanded view of the iron-air battery configurations comprising back plates, current collectors, electrodes, electrolyte compartment and sealing gaskets.

Figure 3 Three electrolyte flow compartments: a) original iron-air battery electrolyte compartment No.1 and modified electrolyte compartments manufactured by 3D printing b) No. 2 and c) No. 3 .

Figure 4 Twenty local oval electrodes of $0.61 \mathrm{~cm}^{2}$ area evenly distributed over an area of $25 \mathrm{~cm}^{2}$ exposed to the electrolyte.

Figure 5 Experimental layout of the electronic and electrolyte circuits including the data acquisition system used to measure the current through each electrode, the pressure drop across the entrance and exit of the electrolyte, the potentiostat and the centrifugal pump. The solution was continuously purged with $\mathrm{N}_{2}$ in the reservoir.

Figure 6 I vs. E plots for electrodes in each cell compartment b) Electrolyte compartment 1, b) Electrolyte compartment 2, and c) Electrolyte compartment 3, from $10 \mathrm{dm}^{3} \mathrm{~h}^{-1}\left(\mathrm{v}=2.8 \mathrm{~cm} \mathrm{~s}^{-1}\right)$ a) to $100 \mathrm{dm}^{3} \mathrm{~h}^{-1}(\mathrm{v}=$ $\left.27.7 \mathrm{~cm} \mathrm{~s}^{-1}\right)$ in increments of $10 \mathrm{dm}^{3} \mathrm{~h}^{-1}\left(\mathrm{v}=2.8 \mathrm{~cm} \mathrm{~s}^{-1}\right)$. The electrolyte used to obtain the limiting current was $5 \times 10^{-3} \mathrm{Cu}$ (II) $\mathrm{mol} \mathrm{dm}^{-3}$ in $\mathrm{N}_{2}$ purged $1.5 \mathrm{~mol} \mathrm{dm}^{-3} \mathrm{H}_{2} \mathrm{SO}_{4}$ at $293.15 \mathrm{~K}$.

Figure 7 Ratio $j_{i} / j_{\mathrm{AVG}}$ of each electrode in three different electrolyte compartments: a) compartment 1 manufactured by CNC techniques, b) compartment 2 and c) compartments 3 , manufactured by 3D printing.

Figure $8 j_{i} / j_{\mathrm{AVG}}$ distributions for three different electrolyte compartments at an electrolyte flow rate of $100 \mathrm{dm}^{3} \mathrm{~h}^{-1},\left(18.50 \mathrm{~cm} \mathrm{~s}^{-1}\right)$. The electrolyte solution contained $5 \times 10^{-3} \mathrm{CuSO}_{4}$ in nitrogen purged $1.5 \mathrm{~mol} \mathrm{dm}^{-3} \mathrm{M}$ $\mathrm{H}_{2} \mathrm{SO}_{4}$ at $25{ }^{\circ} \mathrm{C}$ : a) electrolyte compartment 1, b) electrolyte compartment 2 and c) electrolyte compartment 3.

Figure 9 Pressure drop across the electrolyte compartments $v s$. Reynolds number, compared with the pressure drop values reported in the literature for the FM01-LC electrolyser compartments [15].

Figure 10 The mass transfer coefficient of electrodes in electrolyte compartments 1 and $2, v s$. the pressure drop. 


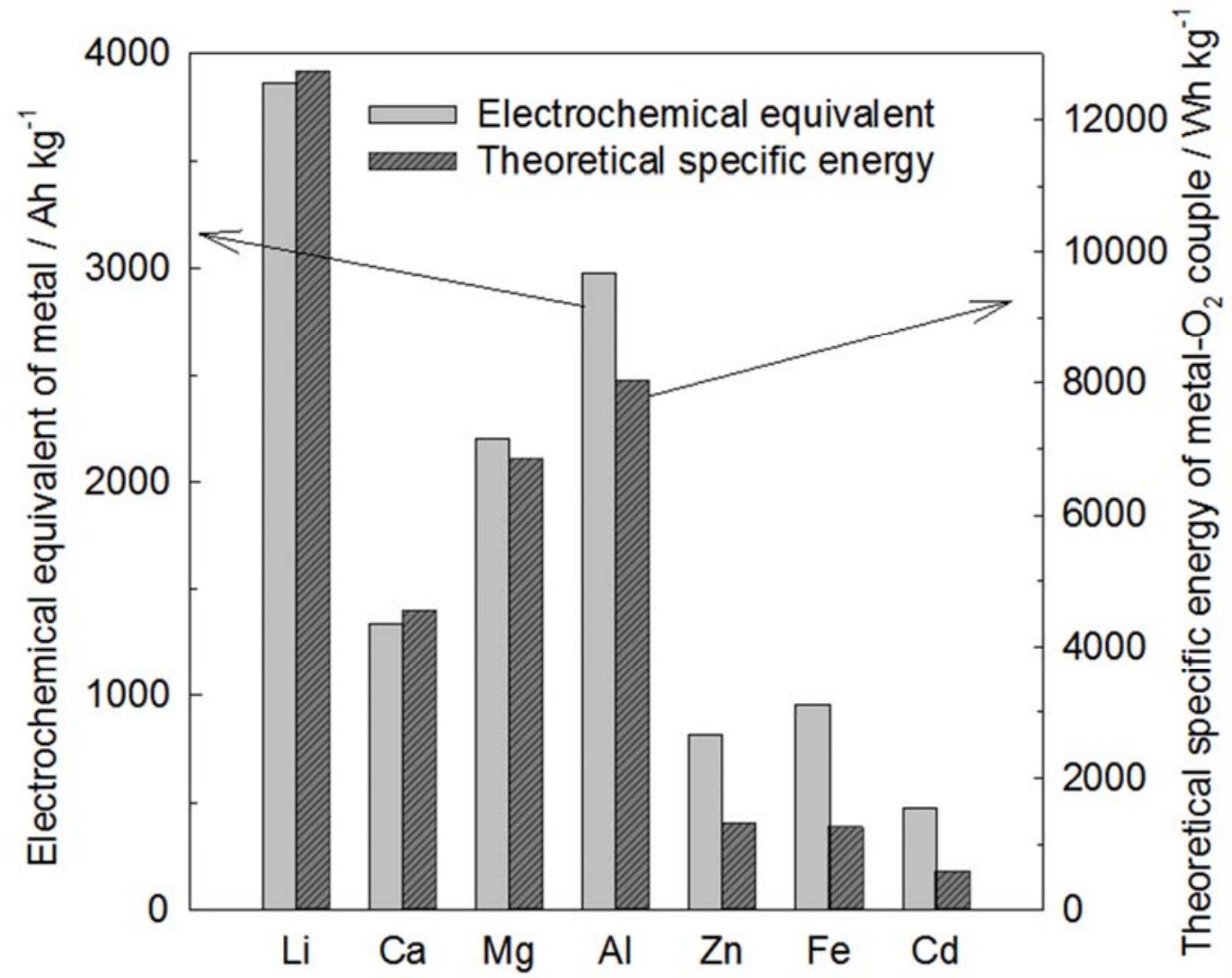

Figure 1 


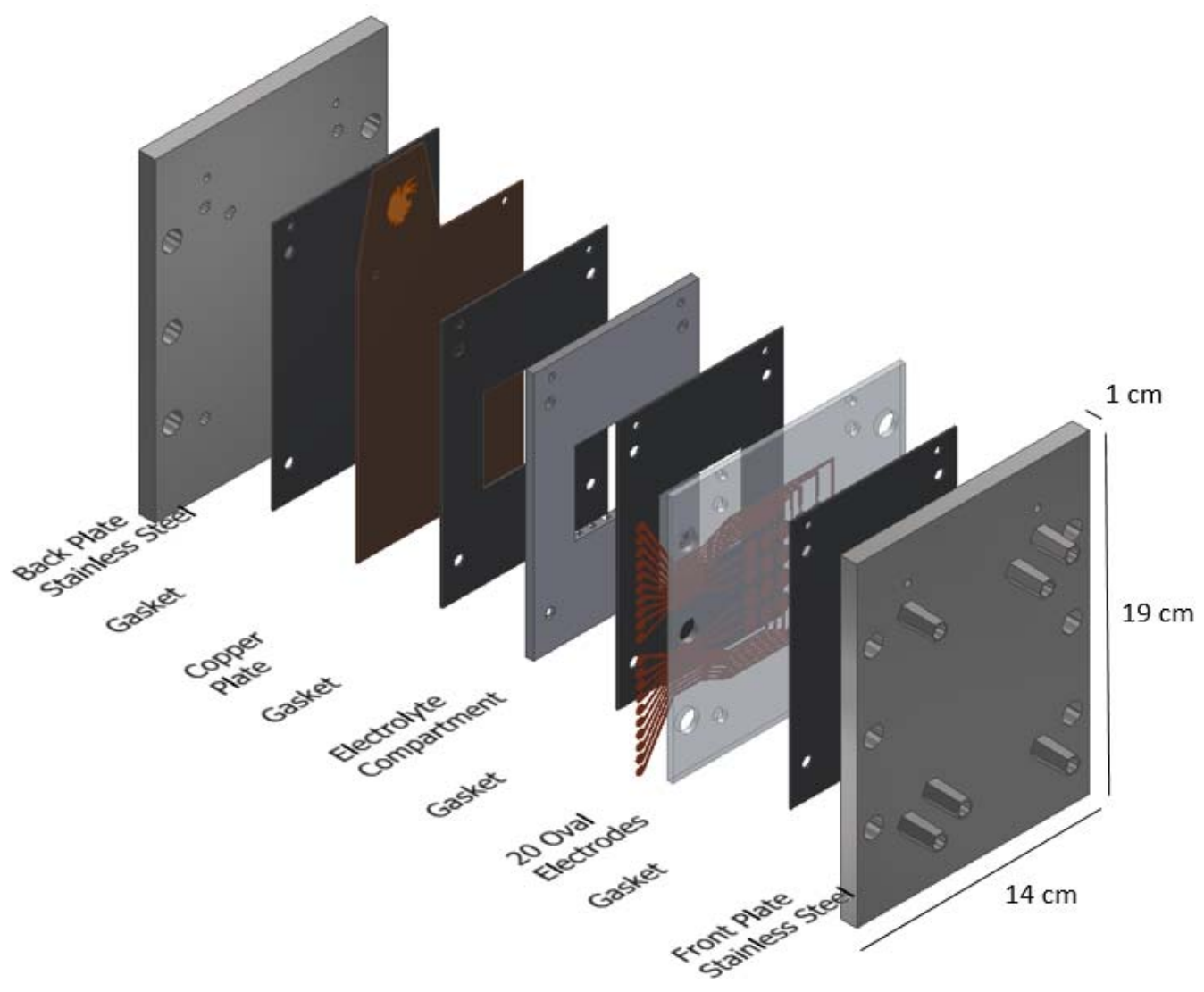

Figure 2 


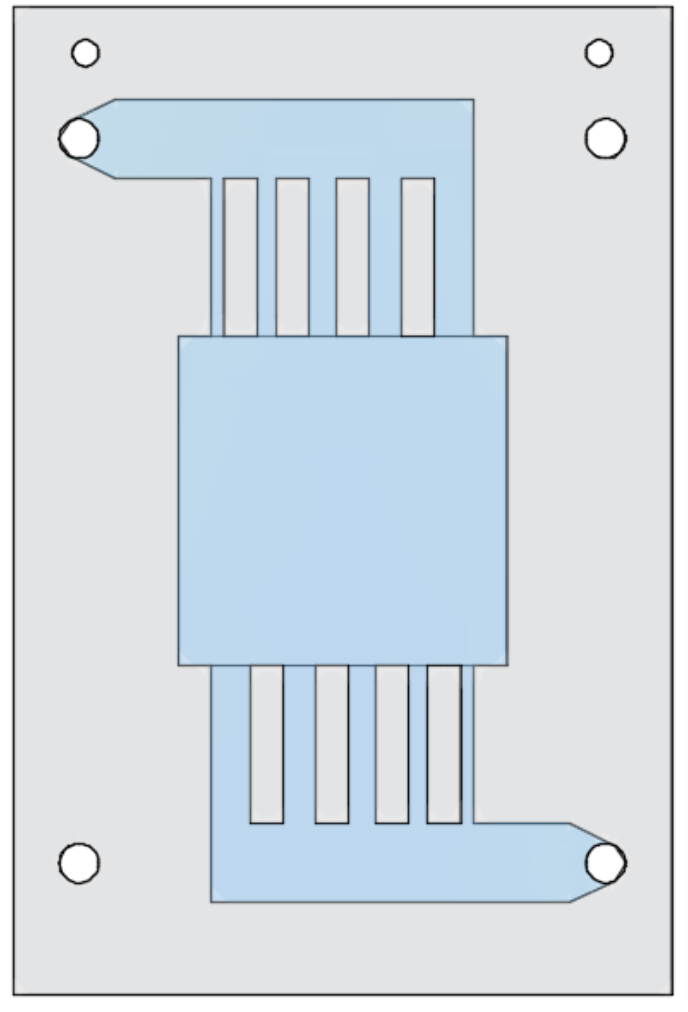

Figure 3a)

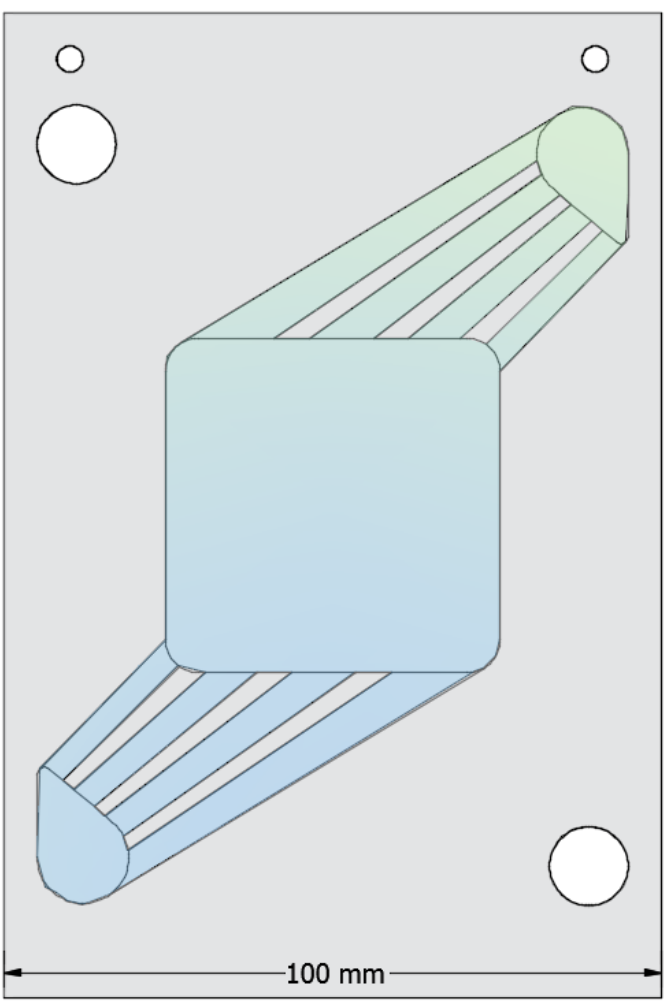

Figure 3b)

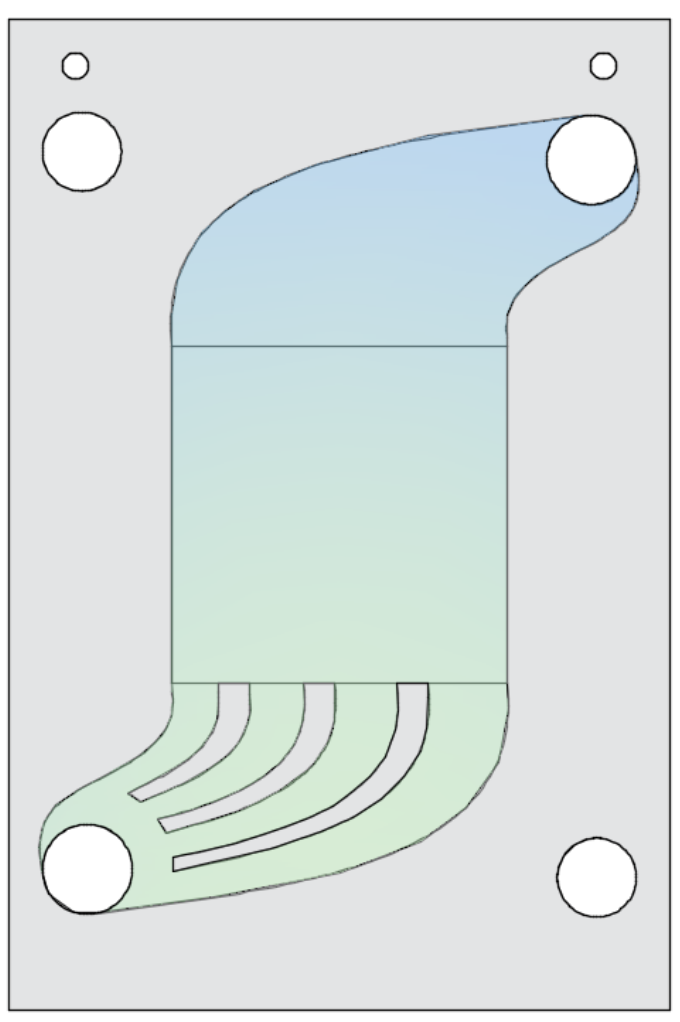

Figure 3c) 


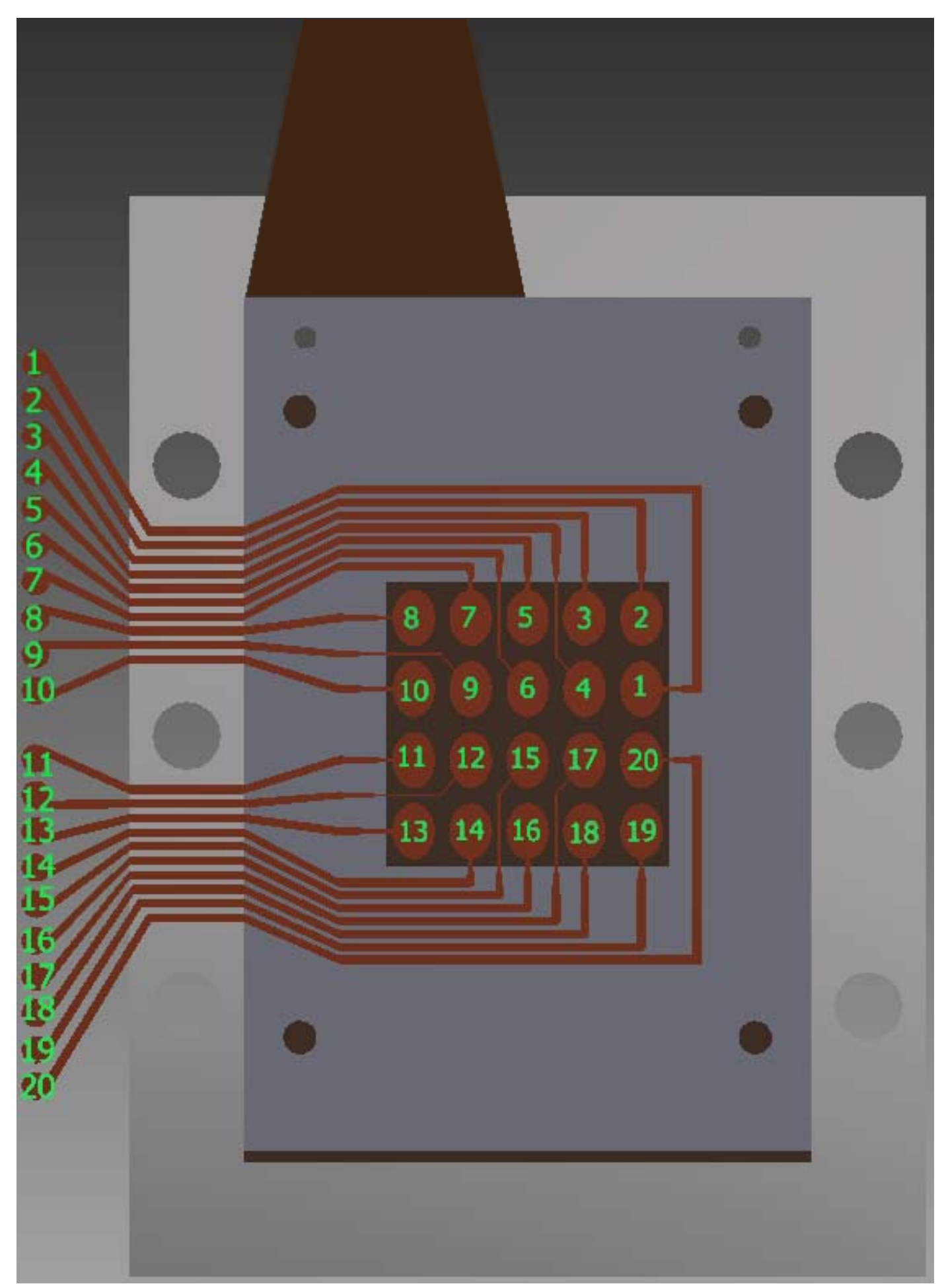

Figure 4 


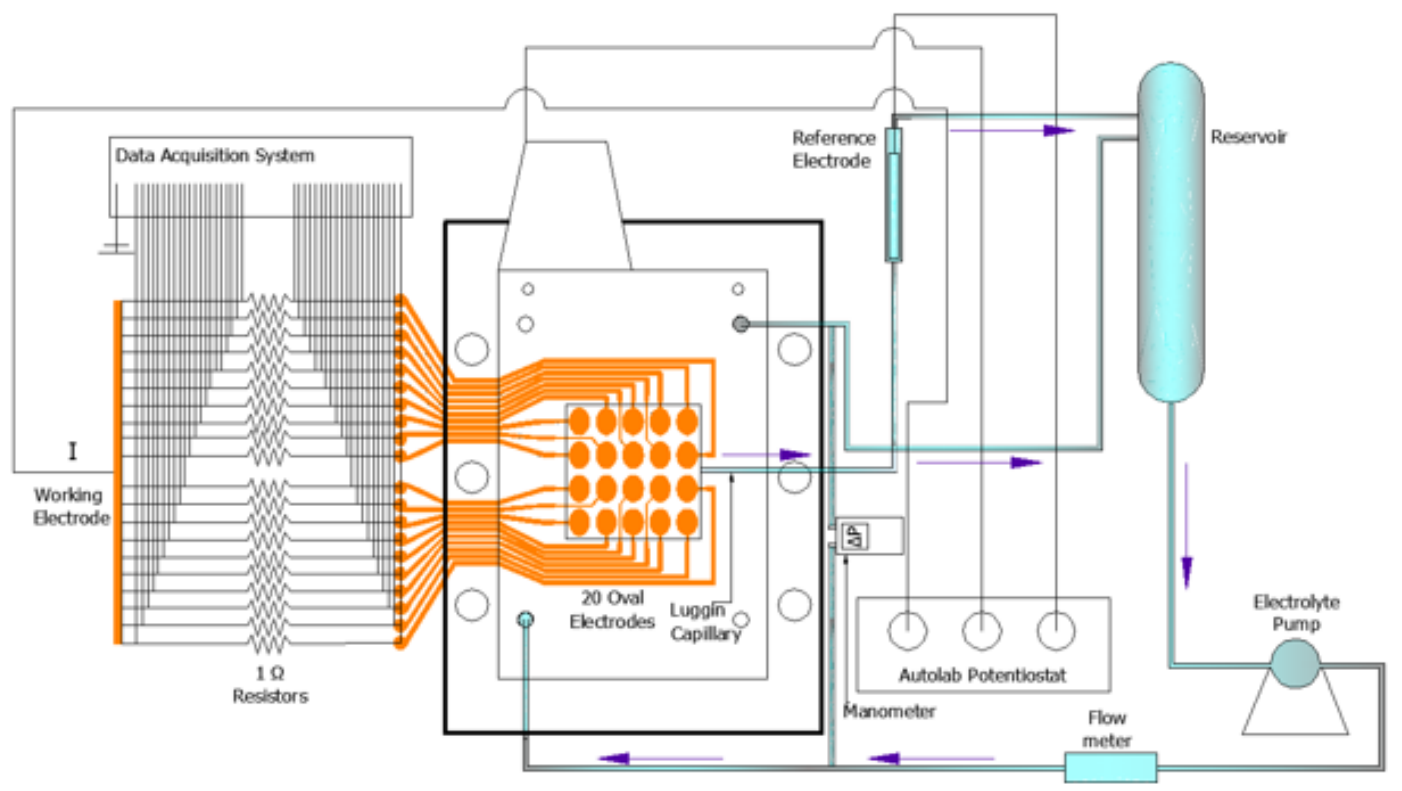

Figure 5 


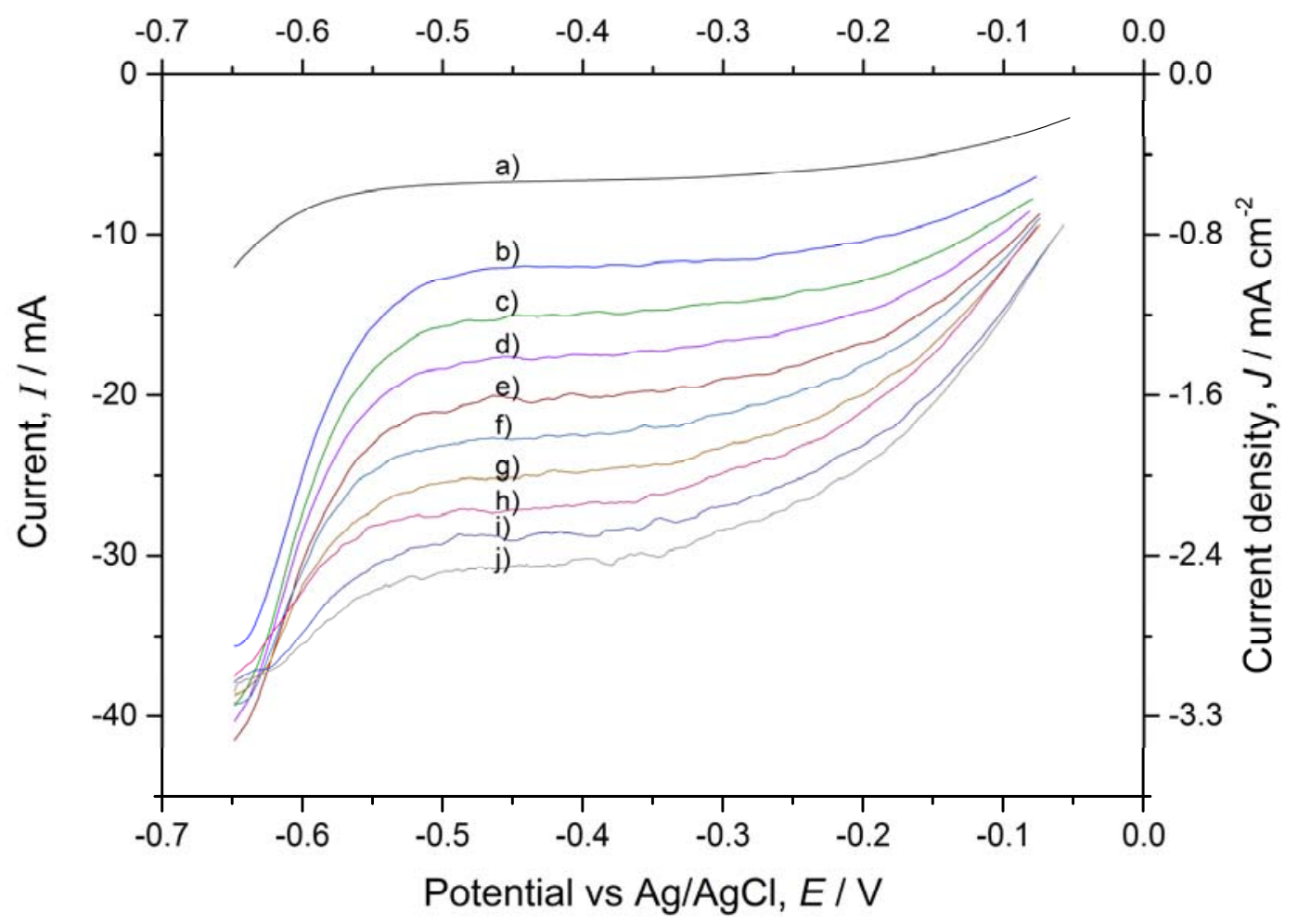

Figure 6a) 


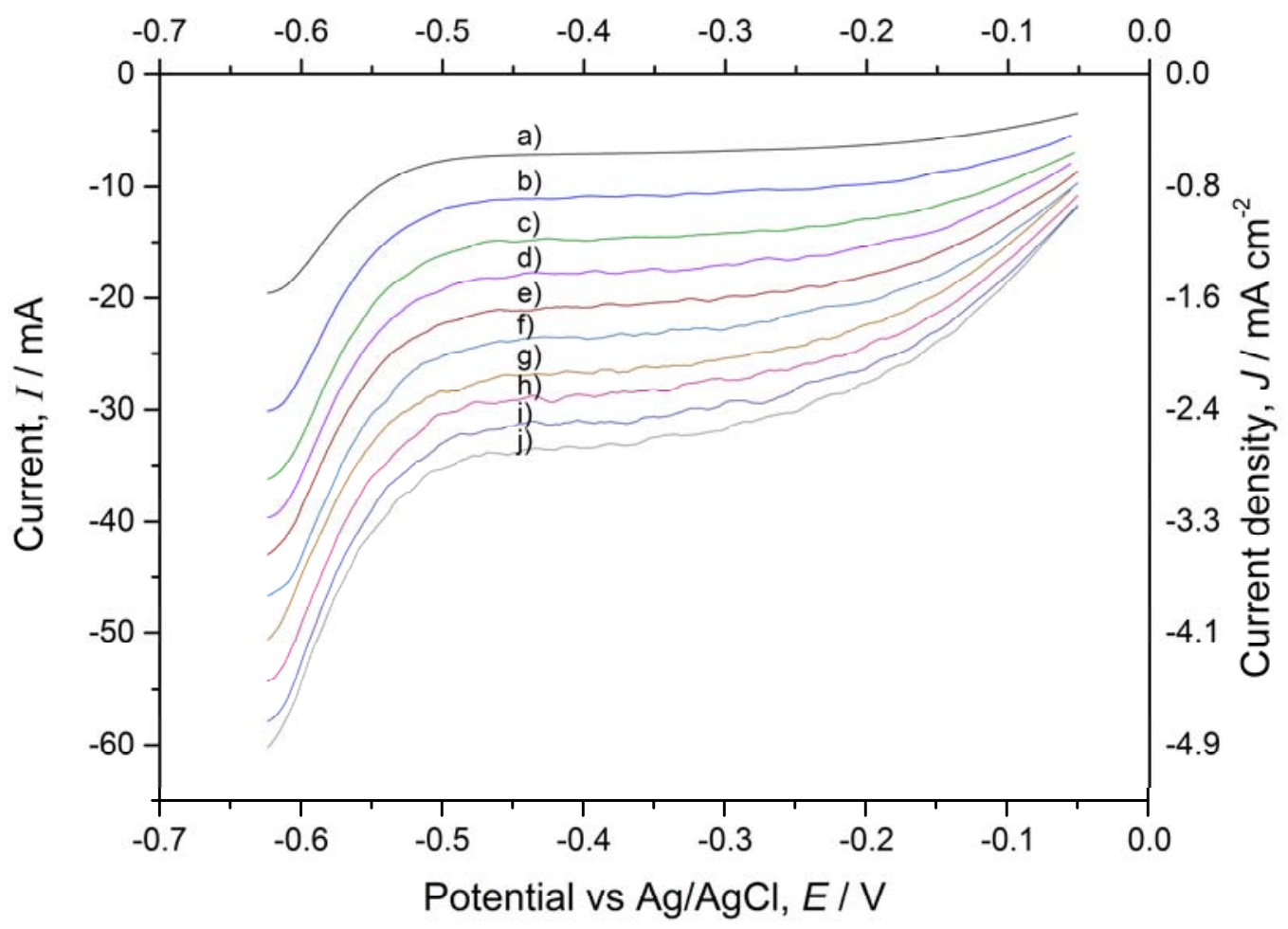

Figure 6b) 


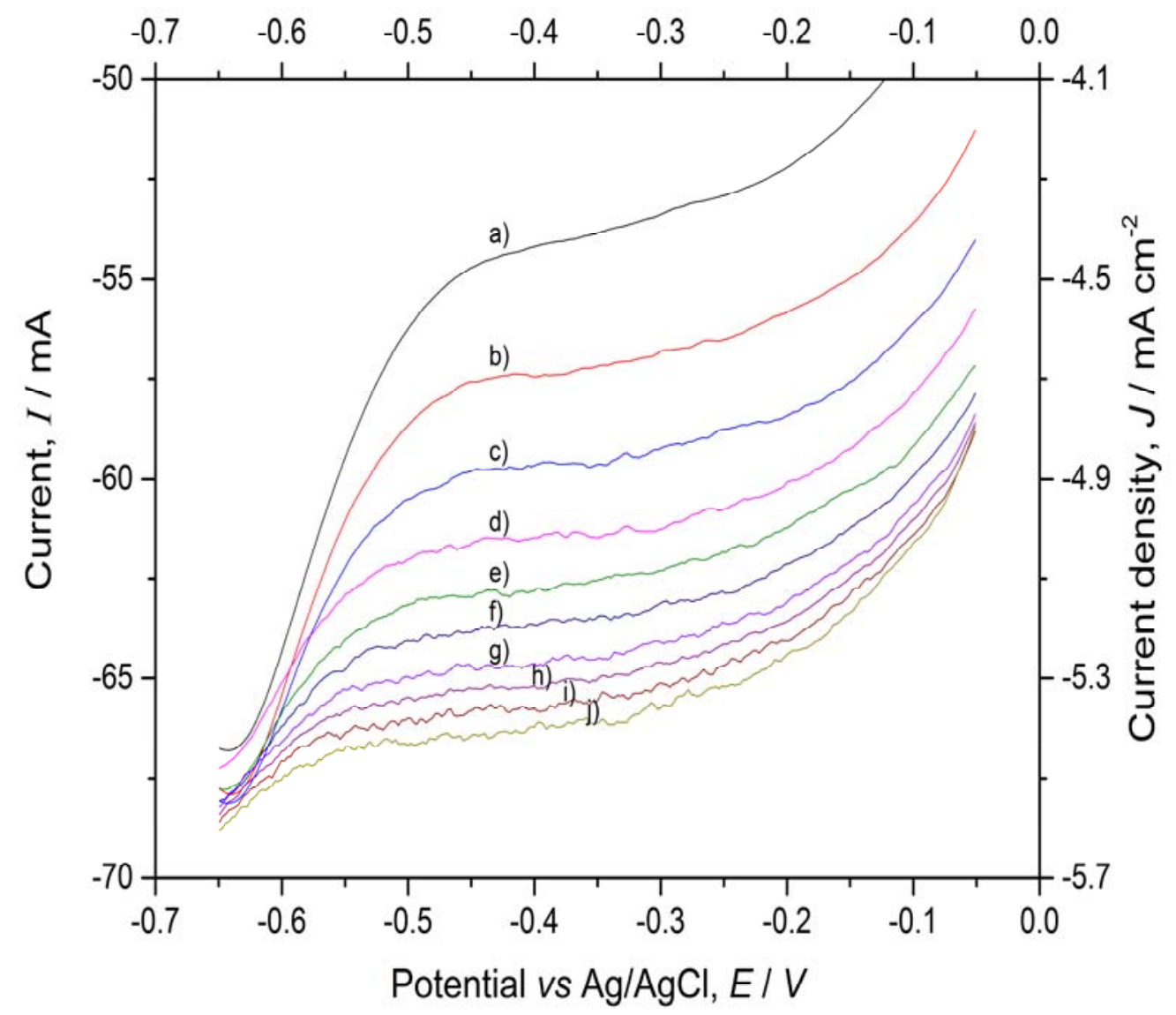

Figure 6c) 

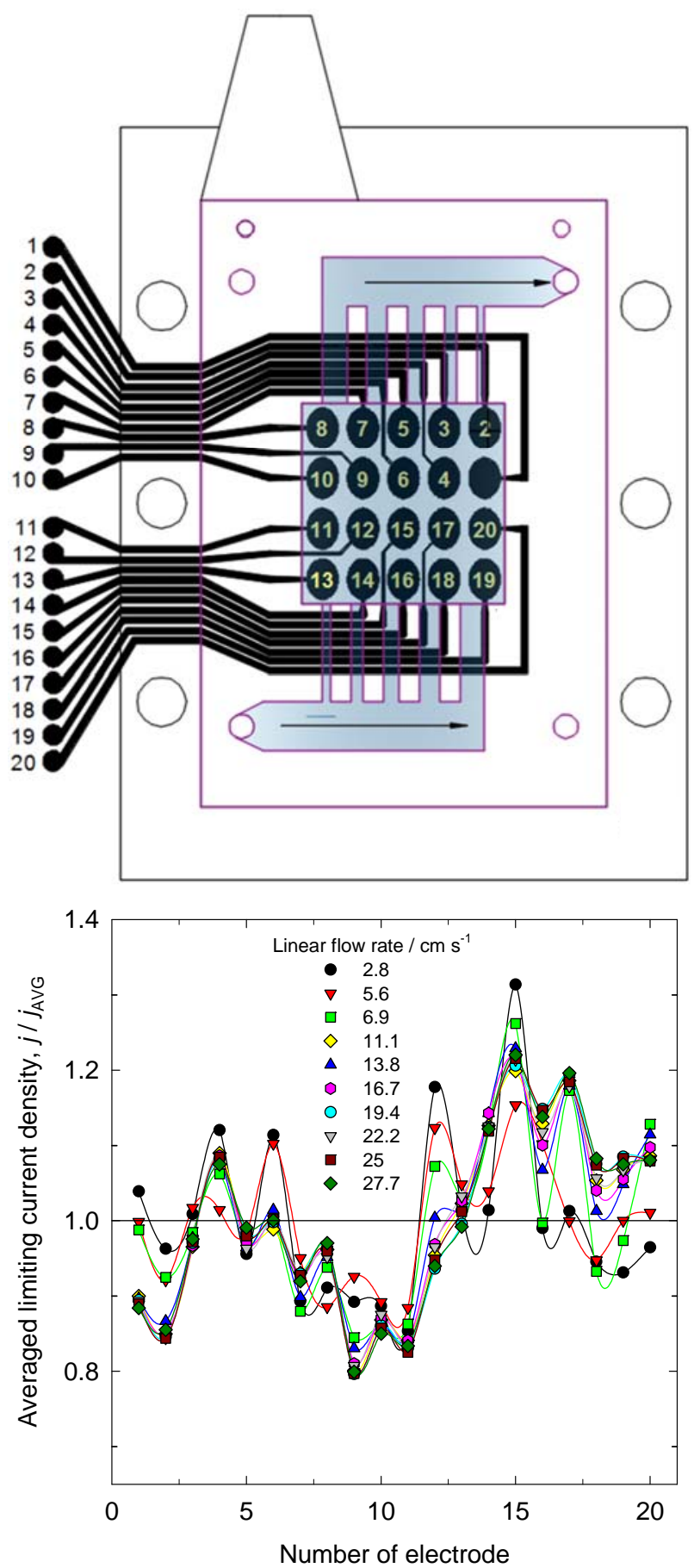

Figure 7a) 

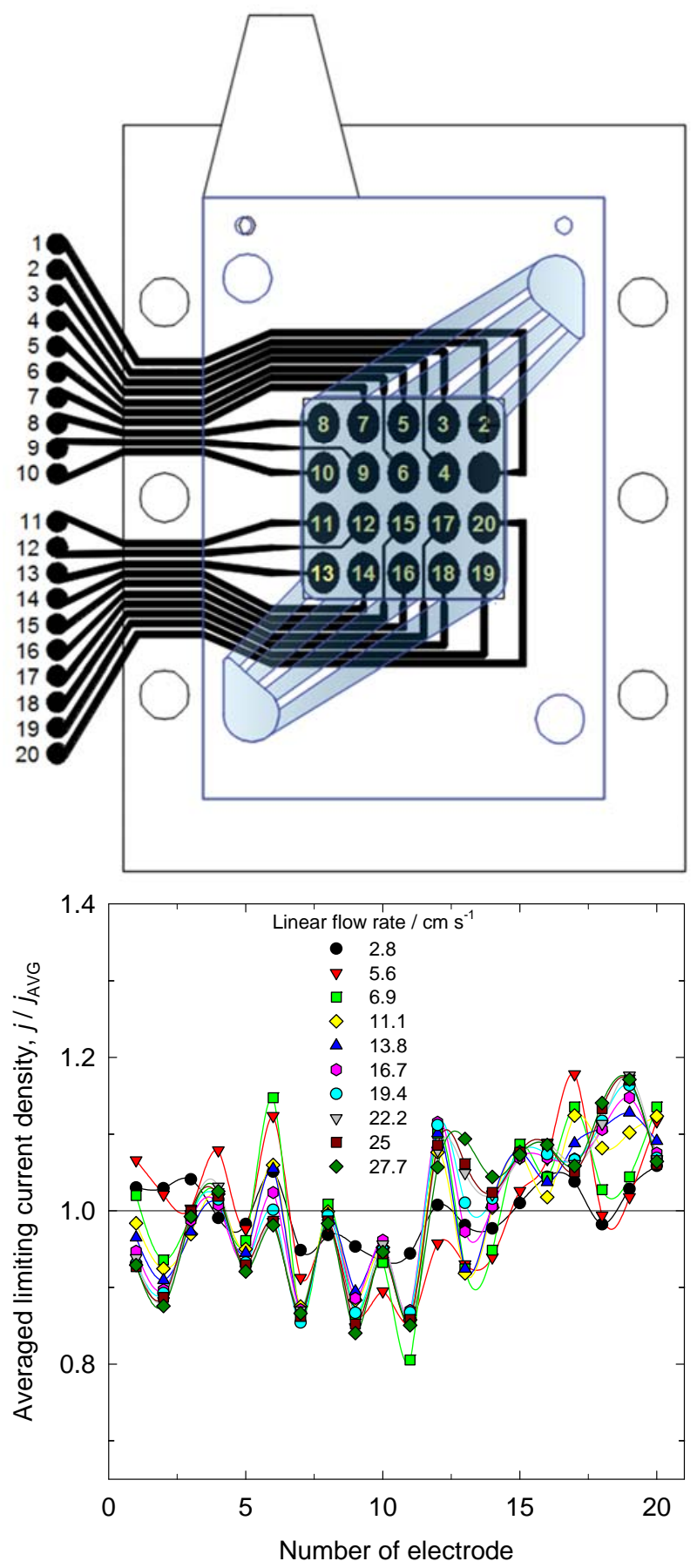

Figure 7b) 

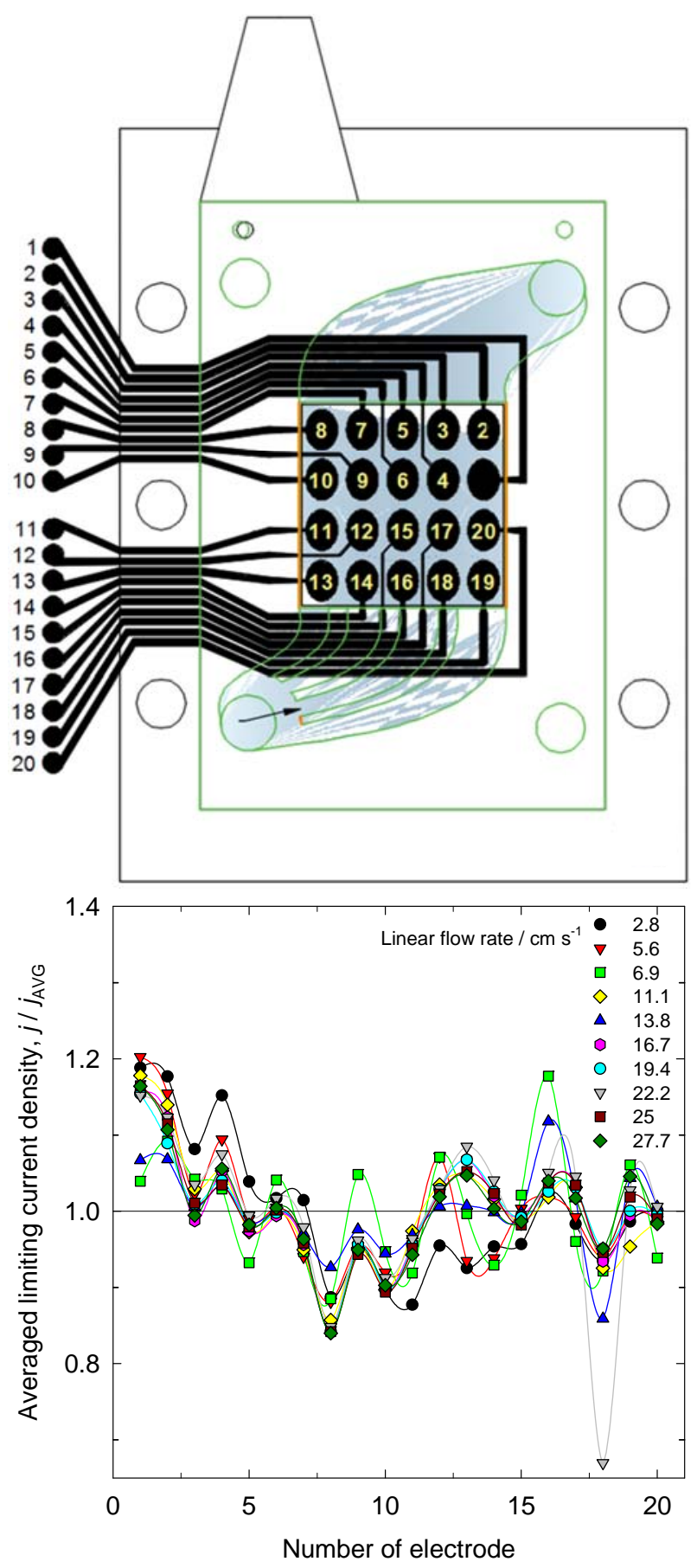

Figure 7c) 


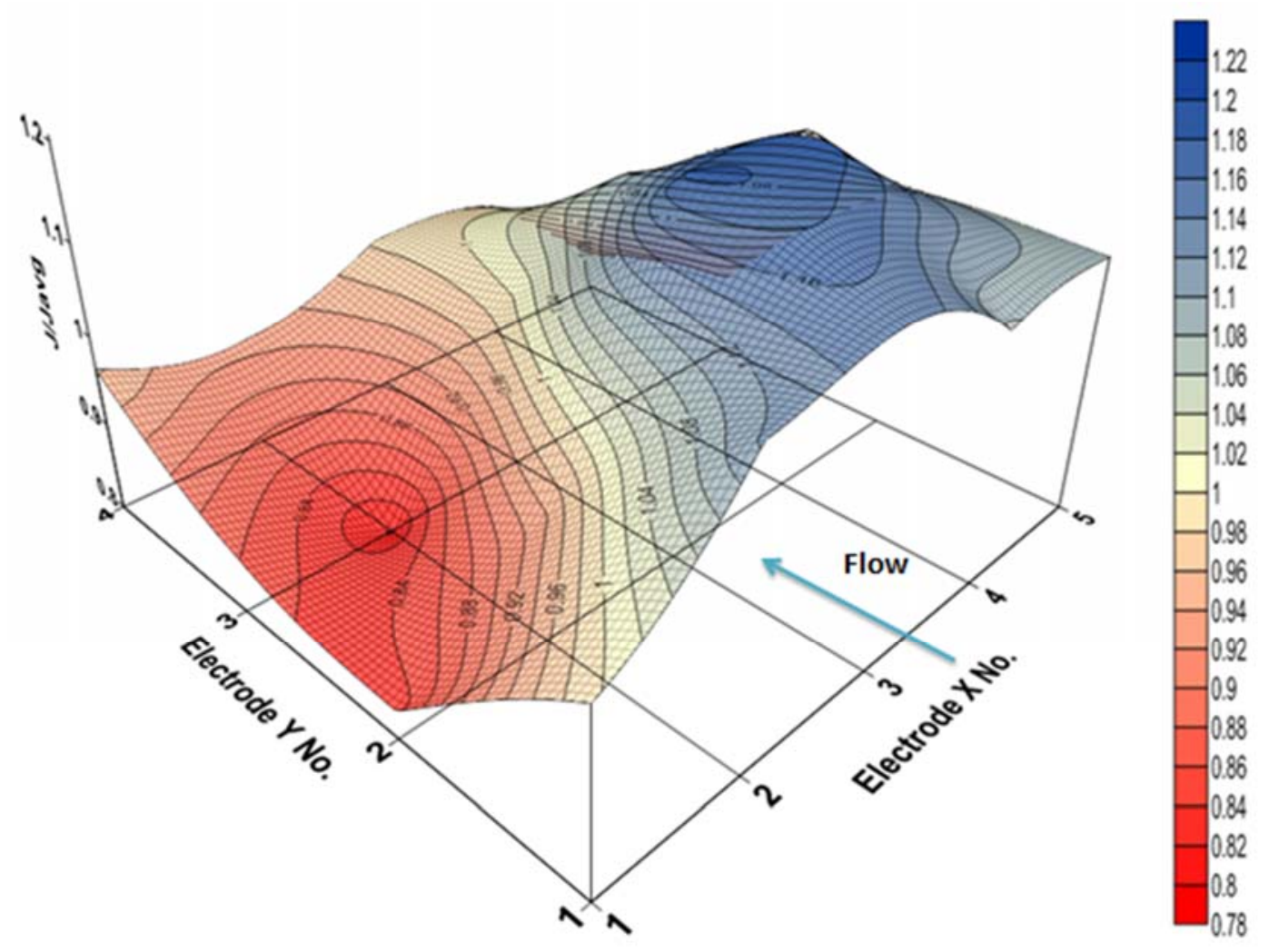

Figure 8a) 


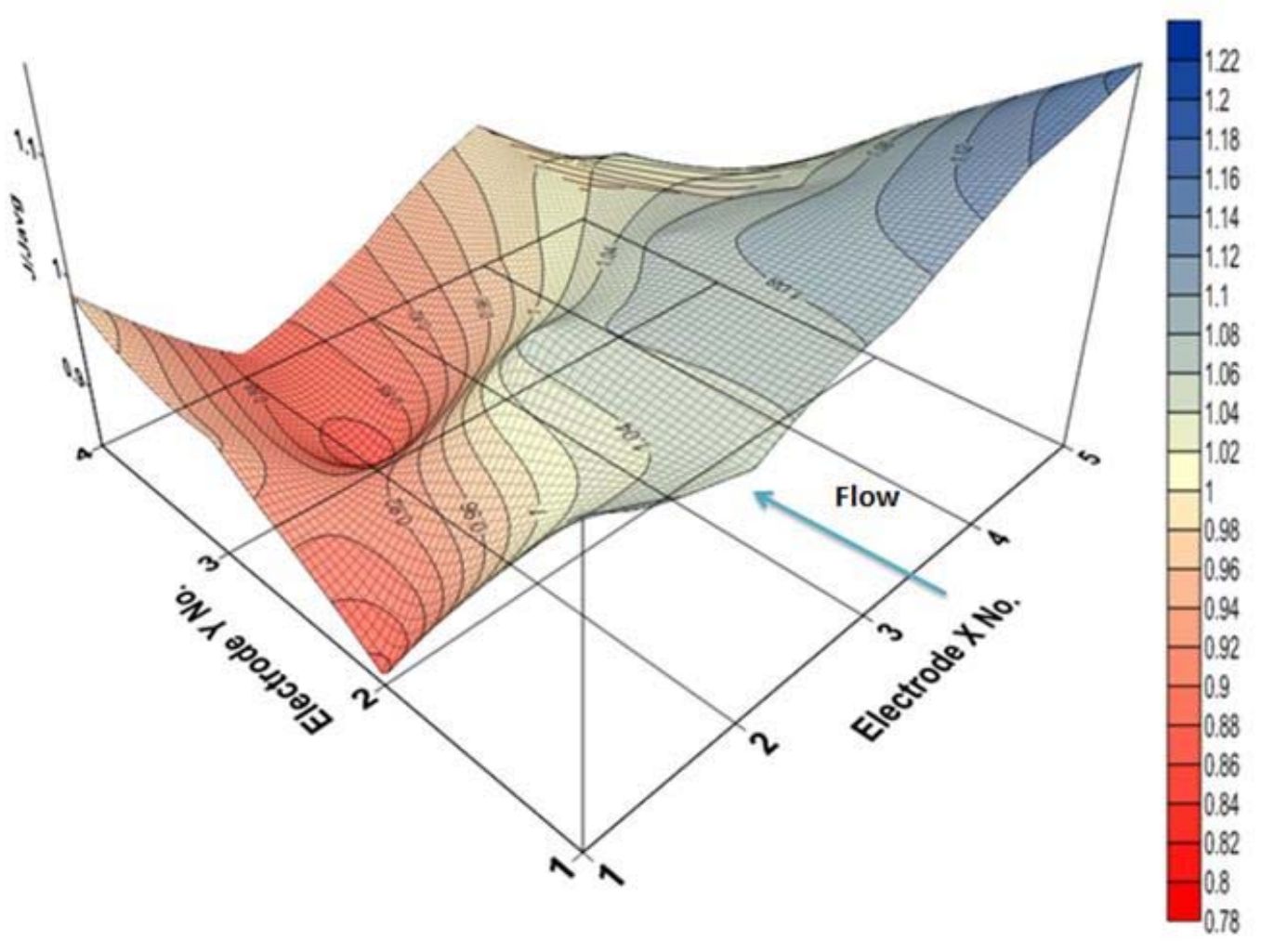

Figure 8b) 


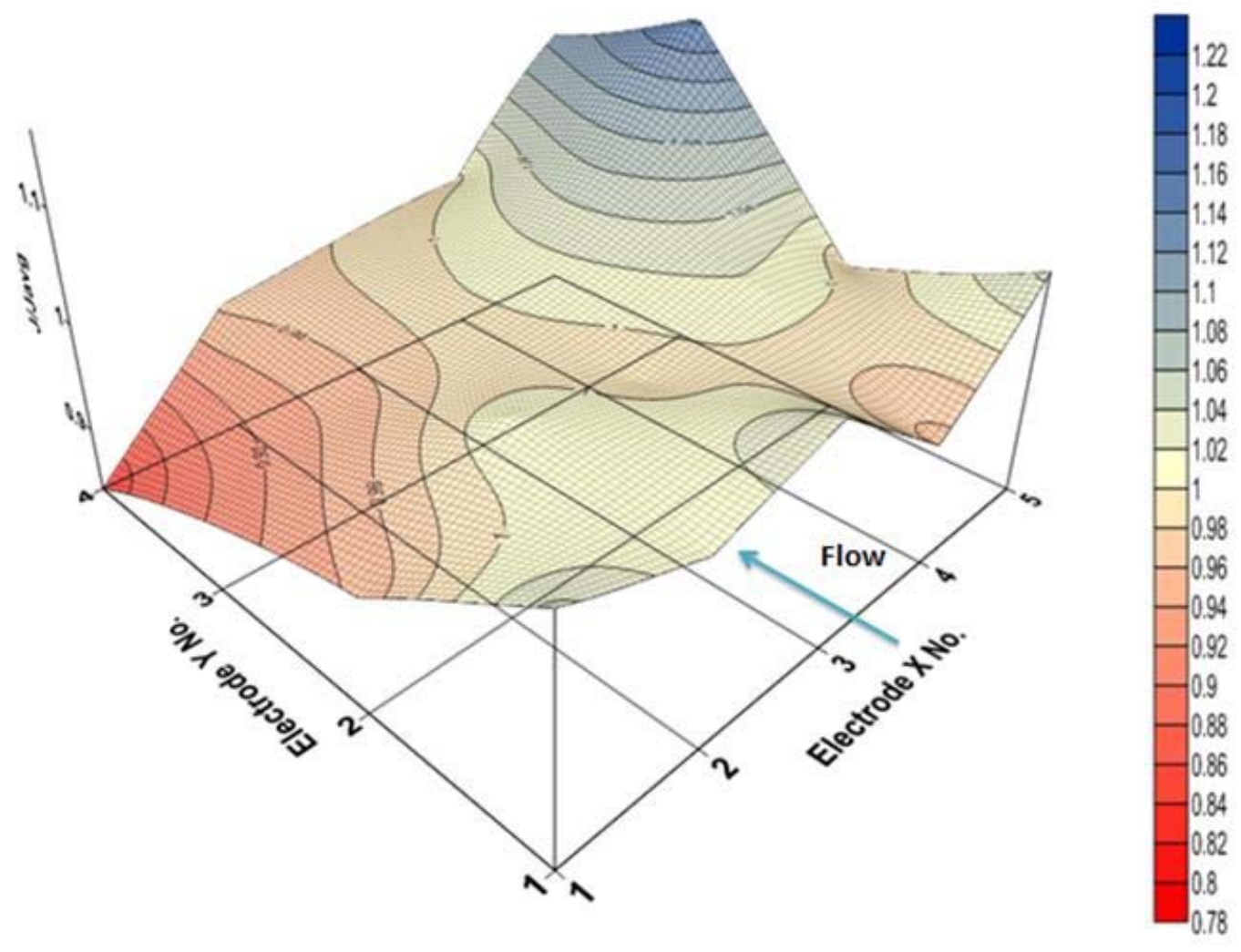

Figure 8c) 


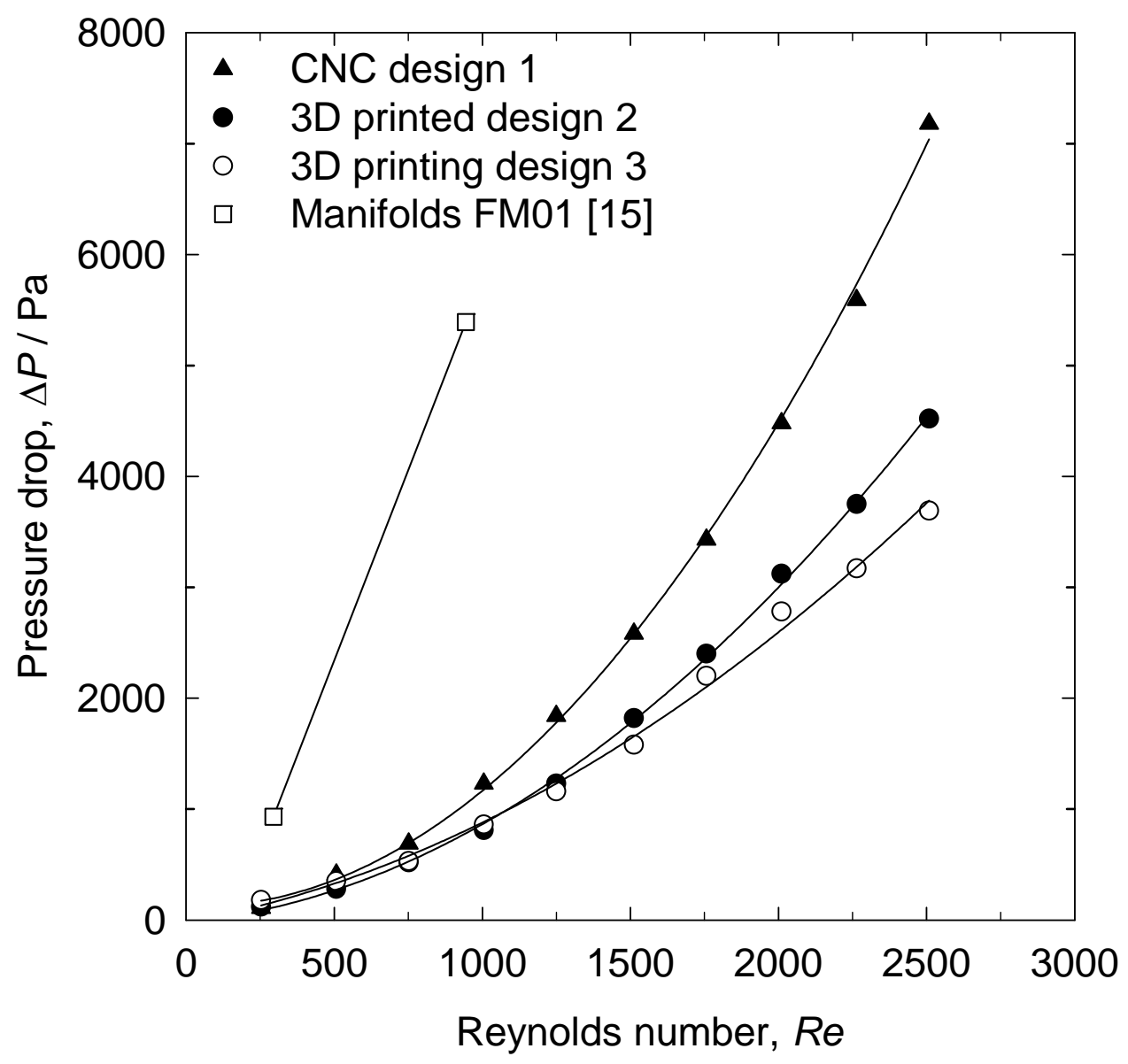

Figure 9 


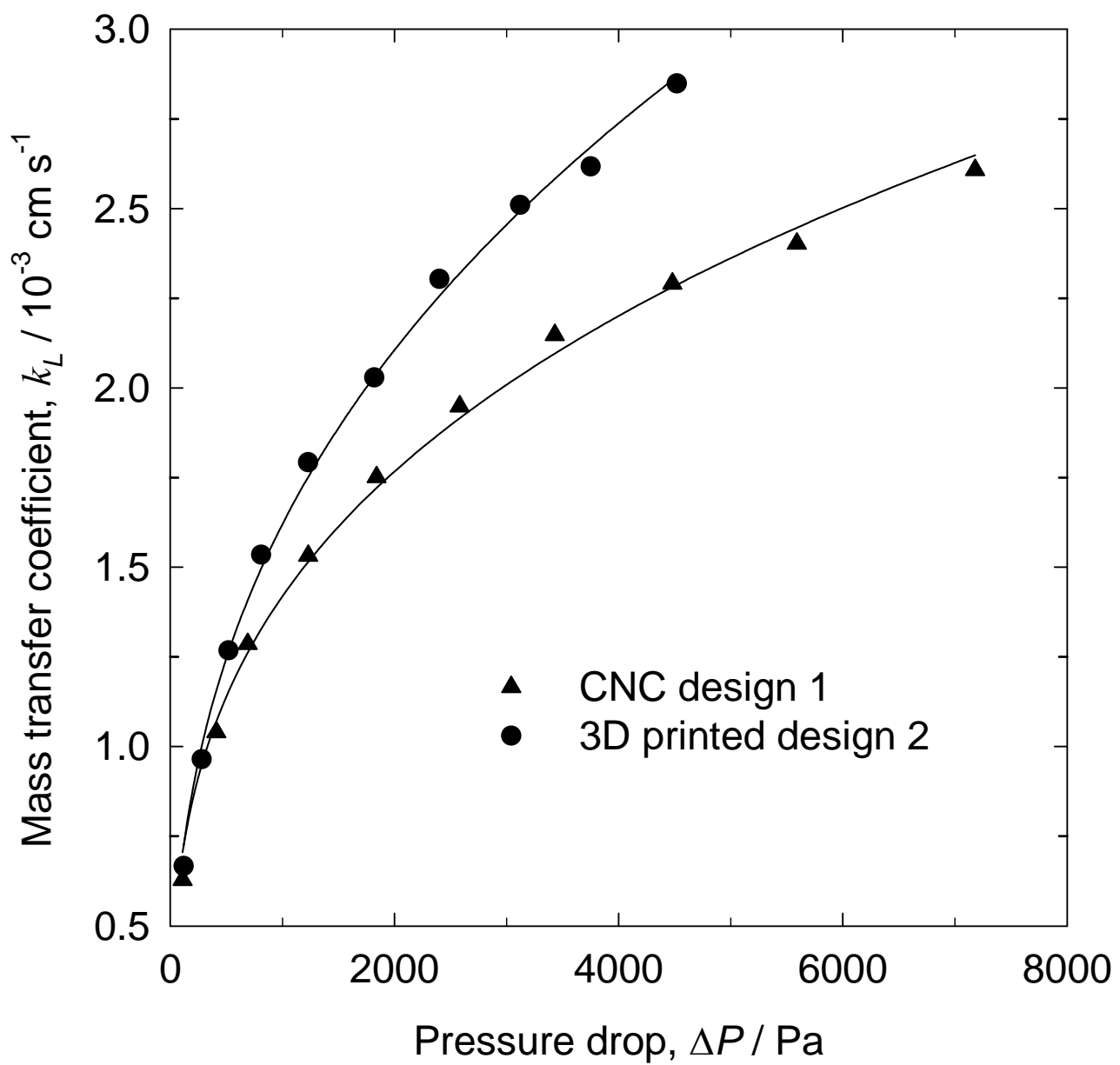

Figure 10 